\title{
Colloid deposition experiments as a diagnostic tool for biomass attachment onto bioproduct adsorbent surfaces
}

\author{
Canan Tari, ${ }^{1 \dagger}$ RamiReddy Vennapusa, ${ }^{2 \dagger}$ Rosa B Cabrera ${ }^{2}$ and \\ Marcelo Fernández-Lahore ${ }^{2 *}$ \\ ${ }^{1}$ Department of Food Engineering, Izmir Institute of Technology, Urla, Izmir 35430, Turkey \\ 2 Downstream Processing Laboratory, Jacobs University, Campus Ring 1, D-28759 Bremen, Germany
}

\begin{abstract}
BACKGROUND: Detrimental processing conditions can be expected in any downstream operation where direct contacting between a crude feedstock and a reactive solid phase is supposed to occur. In this paper we have investigated the factors influencing intact yeast cells deposition onto anion and cation exchangers currently utilized for expanded-bed adsorption of biotechnological products. The aim of this study was twofold: (a) to confirm previous findings relating biomass deposition with surface energetics according to the extended Derjaguin, Landau, Verwey and Overbeek theory (XDLVO) theory; and (b) to provide a simple experimental tool to evaluate biomass deposition onto process surfaces.
\end{abstract}

RESULTS: Biomass deposition experiments were performed on an automated workstation utilizing a packedbed format. Two commercial ion exchangers intended for the direct capture of bioproducts in the presence of suspended biological particles were employed. Intact yeast cells in the late exponential phase of growth were selected as model bio-colloids. Cell deposition was systematically evaluated as a function of fluid-phase conductivity and quantitatively expressed as a biomass deposition parameter $(\alpha)$.

CONCLUSION: $\alpha \leq 0.15$ was established as a criterion to reflect negligible biomass adhesion to the process support(s). Biomass deposition experiments further confirmed predictions made on the basis of free interfacial energy calculations as per the extended DLVO approach.

() 2008 Society of Chemical Industry

Keywords: direct capture; bio-colloids; biomass deposition; EBA; attachment efficiency; interfacial energy

$\begin{array}{ll}\text { NOTATION } \\ A & \text { Hamaker constant (kT) } \\ \text { AB } & \text { Acid-base } \\ \text { AU } & \text { Absorbance units } \\ \text { CFT } & \text { Colloid filtration theory } \\ C & \text { Final concentration } \\ C_{0} & \text { Initial concentration } \\ d_{\mathrm{c}} & \text { Diameter of collector (m) } \\ \text { DEAE } & \text { Diethylaminoethyl- } \\ \text { DLVO } & \text { Derjaguin, Landau, Verwey and Overbeek } \\ d_{\mathrm{p}} & \text { Diameter of yeast cells (m) } \\ \text { EBA } & \text { Expanded bed adsorption } \\ \text { EL } & \text { Electrostatic interaction } \\ H & \text { Separation distance (m) } \\ k_{\mathrm{d}} & \text { Deposition rate coefficient ( } \mathrm{s}^{-1} \text { ) } \\ k_{\mathrm{d} \text { fav }} & \text { Deposition rate coefficient for favourable } \\ & \left.\text { deposition ( }{ }^{-1}\right) \\ L & \text { Length of column (m) }\end{array}$

$\begin{array}{ll}\text { LW } & \text { Lifshitz-van der Waals interaction } \\ \mathrm{PV} & \text { Pore volume }(\mathrm{mL}) \\ \mathrm{Pe} & \text { Peclet number } \\ \mathrm{Re} & \text { Reynolds number } \\ \mathrm{SP} & \text { Sulfopropyl- } \\ U & \text { Superficial fluid velocity }\left(\mathrm{ms}^{-1}\right) \\ U^{\text {TOT }} & \text { Total interaction energy }(\mathrm{kT}) \\ \text { XDLVO } & \text { Extended DLVO } \\ \varepsilon & \text { Porosity } \\ \alpha & \text { Attachment efficiency parameter } \\ \eta_{0} & \text { Single-collector contact efficiency }\end{array}$

\section{INTRODUCTION}

Detrimental processing conditions can be expected in any downstream operation where direct contact between a crude feedstock and a reactive solid phase is supposed to occur. This type of unit operation

* Correspondence to: Marcelo Fernández-Lahore, Downstream Processing Laboratory, Jacobs University, Campus Ring 1, D-28759 Bremen, Germany

E-mail: m.fernandez-lahore@jacobs-university.de

†These authors contributed equally to the work.

Contract/grant sponsor: BID 1201/OC AR 649 PICT 08352

Contract/grant sponsor: Jacobs University; contract/grant number: IUB/2130-90050

(Received 30 August 2007; revised version received 7 November 2007; accepted 8 November 2007)

DOI: $10.1002 /$ jctb. 1852 
has the potential to combine solids removal, product concentration, and partial purification in a single processing step. However, it is already known that suspended biological particles will interact with adsorbent materials. In the particular case of expanded bed adsorption (EBA) interaction phenomena may lead to the development of poor system hydrodynamics, and therefore impaired sorption performance, under real process conditions. ${ }^{1}$ Biomass deposition would also result in increased buffer consumption. ${ }^{2}$

The principles of colloid chemistry can be applied to explain biomass-adsorbent attachment at the local (particle) level. ${ }^{3}$ Biomass adhesion to process supports has the potential to be strongly influenced by longrange electrodynamic Lifshitz-van der Waals (LW) and electrostatic (EL) and short-range acid-base (AB) interfacial interactions. EL interactions arise from the existence of overlapping double layers of counterions near charged surfaces in aqueous media and are accessible by determination of the zeta potential. LW and $\mathrm{AB}$ forces are experimentally accessible via contact angle measurement with three diagnostic liquids.

Earlier studies on biomass-adsorbent interactions pointed out that interactions between (positively charged) anion exchangers and (negatively charged) biological particles were the most problematic systems to deal with. Due to the obvious electrostatic nature of such interaction, a single property of these interacting bodies, i.e., the zeta potential, has been recently proposed for a better understanding and prediction of biomass-adsorbent interactions. ${ }^{4,5}$ It is now understood that Coulomb-type interaction are predominant when the basic nature of the process material and the characteristics of the microbial species/strains is kept similar. Moreover, charge effects are only predominant in deposition systems where strongly charged materials are under consideration. Therefore, a single measure like the particle zeta potential cannot be considered a universal approach to process/material design. Some studies have found a better correlation between surface energy, calculated by the three liquid contact angle method, and microbial adhesion on different solid supports at constant solution chemistry. ${ }^{6}$

The mechanistic understanding of the transport and deposition of microbial cells onto natural and process surfaces has significant interest in various environmental and bioprocess situations. A better description of the factors controlling the transport of biological particles is important for the appropriate design of direct-contact downstream operations, as well as for the development of novel adsorbent materials. Traditionally, microbial deposition has been studied employing packed beds. A population of biological particles is introduced into such systems and the suspended cell or cell debris effluent is monitored as a function of process time. This type of experiment can provide useful and quantitative information when assessing factors like cell size and shape, microorganism strain, growth phase, bead size, surface coatings, fluid velocity, and ionic strength on cell deposition onto process media. ${ }^{7}$

Mathematical models of microbial transport in porous media most commonly utilizes the advection-dispersion equation as derived by mass balance principles. ${ }^{8,9} \mathrm{~A}$ common approach to evaluate biomass deposition in laboratory packed-bed experiments employs the 'clean-bed' filtration model or colloid filtration theory (CFT). This model is valid for steady-state systems which are initially free of biomass particles and where axial dispersion can be neglected (Pe $\geq 20) .{ }^{10}$ Within the CFT, mass transport phenomena are accounted by the 'single-collector contact efficiency' $\left(\eta_{0}\right)$, while the physicochemical phenomena related to biomass attachment are reflected by the 'attachment efficiency parameter' $(\alpha) .{ }^{11}$ At larger biomass loads, $\alpha$ values are controlled not only by cell-support interactions but also by the amount of previously attached biomass particles. This implies that attached biomass particles onto the process surface can effectively reduce deposition by a socalled collector 'blocking' effect. ${ }^{9}$ On the other hand, increased biomass attachment can result from cellto-cell aggregation: a phenomena known as system 'ripening'. 12

In this paper we have investigated the factors influencing intact yeast cell deposition onto anion and cation exchangers currently utilized for expanded-bed adsorption of biotechnological products. These two systems represent examples of 'interacting' versus 'noninteracting' situations, which are relevant in industrial practice. The aim of this study was twofold: (a) to confirm previous findings relating biomass deposition with surface energetics according to the extended Derjaguin, Landau, Verwey and Overbeek (XDLVO) theory; and (b) to provide a simple experimental tool to evaluate biomass deposition onto process surfaces.

\section{MATERIAL AND METHODS Materials}

Chromatographic matrices and columns were purchased from GE Healthcare (Munich, Germany). Water was Milli-Q quality. All other chemicals were of analytical grade.

\section{Yeast cells}

Saccharomyces cerevisiae cells were cultivated, harvested at late exponential phase, and washed three times with $10 \mathrm{mmol} \mathrm{L}^{-1}$ buffer solutions, as previously described. ${ }^{13}$ Cells were employed immediately after harvest and washing for deposition experiments. Intact yeast cell diameter was taken as $8 \mu \mathrm{m}$. A Hamaker constant value of $0.34 \mathrm{kT}$ was utilized according to previous work based on contact angle determinations. ${ }^{14}$

\section{Zeta potential determination}

Zeta potential was measured with a Zetasizer Nano ZS (Malvern Instruments, Malvern, UK). Particles were 
contacted with $20 \mathrm{mmol} \mathrm{L}^{-1}$ sodium phosphate buffer at $\mathrm{pH} 7.6$ until equilibrium was reached and further diluted to appropriate particle count $(\sim 200$ cells total count) before measuring the zeta potential. Zeta potentials were calculated from the electrophoretic mobility data as per Smoluchowski's equation. ${ }^{15}$ All measurements were made in triplicate.

\section{Biomass deposition experiments}

Biomass deposition experiments were performed in Tricorn $^{\mathrm{TM}}$ glass chromatographic columns ( $5 \mathrm{~mm}$ internal diameter, $50 \mathrm{~mm}$ length) packed with Streamline ${ }^{\mathrm{TM}}$ adsorbents (GE Healthcare, Munich, Germany). These macroporous adsorbents are made of crosslinked agarose $(6 \%)$ containing a crystalline quartz core. Average bead (collector) diameter was taken as $200 \mu \mathrm{m}$ (spherical particles with size distribution $100-300 \mu \mathrm{m})$. The matrix was uniformly packed as judged by residence time distribution studies, performed with $5 \%$ acetone as a tracer. Bed porosity was estimated as 0.4 . Highly porous frits were utilized in order to allow for non-restricted passage of yeast cell through the system. Biological particle (soft colloid) deposition dynamics was studied by injecting a $4 \mathrm{~mL}$ biomass pulse ( $\sim 10$ pore volumes). Cell concentration was adjusted to $\approx 6.4 \times 10^{7} \mathrm{cell} \mathrm{cm}^{-3}$ by diluting the cell suspension in order to obtain an absorbance value at $600 \mathrm{~nm}(1 \mathrm{~cm}$ path length $) \approx 0.8 \mathrm{AU}$. Cell number was determined employing a Coulter counter (Multisizer $^{\mathrm{TM}}$ 3, Beckman Coulter, Fullerton, CA, USA). Deposition experiments were run in an automated ÄKTA Explorer 100 system (GE Healthcare). A mobile phase composed of phosphate-based buffers $(\mathrm{pH} 7.6)$ at different conductivities $(0.66,2.0,8.4$, 14.0 , and $38.6 \mathrm{mS} \mathrm{cm}^{-1}$ ) was pumped at $76.4 \mathrm{~cm}$ $\mathrm{h}^{-1}$. Particle breakthrough curves were obtained by monitoring the effluent suspension at $600 \mathrm{~nm}$. Regeneration of the material was performed by extensive treatment with $1 \mathrm{~mol} \mathrm{~L}^{-1}$ sodium hydroxide followed by exhaustive rinsing with distilled water.

\section{Parameter calculation}

Cell (colloid) deposition onto collector (adsorbent) beads can be described by model parameters. To compare biomass breakthrough curves quantitatively, the deposition rate coefficient $\left(k_{\mathrm{d}}\right)$ was calculated for each packed-bed experimental run according to the following expression: ${ }^{16}$

$$
k_{\mathrm{d}}=-\frac{U}{\varepsilon L} \ln \left(\frac{C}{C_{0}}\right)
$$

where $U$ is superficial velocity, $\varepsilon$ is the bed porosity, and $L$ is the column length. The value for $C / C_{0}$ corresponding to the initial 'clean bed' condition, i.e., $C / C_{0}$ at 2 pore volumes, was utilized for calculations. The deposition rate coefficient is directly related to the single-collector contact efficiency $\left(\eta_{0}\right)$ and the empirical attachment efficiency $(\alpha)$ according to the following expression:

$$
k_{\mathrm{d}}=\frac{3}{2} \frac{(1-\varepsilon)}{d_{\mathrm{c}} \varepsilon} U \alpha \eta_{0}
$$

where $d_{\mathrm{c}}$ is the diameter of a spherical collector, and $\eta_{0}$ is the single-collector contact efficiency. $\eta_{0}$ can be calculated from published correlations. ${ }^{17}$ The attachment efficiency $(\alpha)$ represents the fraction of collisions between biomass particles suspended in the fluid phase which results in attachment:

$$
\alpha=-\frac{2}{3} \frac{d_{\mathrm{c}}}{(1-\varepsilon) L \eta_{0}} \ln \left(\frac{C}{C_{0}}\right)
$$

Utilizing experimental data from breakthrough of cells from packed beds, the attachment efficiency parameter $(\alpha)$ can be calculated as $\alpha=k_{\mathrm{d}} / k_{\mathrm{d} \text { fav }}{ }^{11}$

\section{RESULTS AND DISCUSSION \\ Physicochemical properties of the cell particles/beaded adsorbents}

The electrokinetic potential of the interacting particles, e.g., the yeast cells versus the beaded adsorbents, were studied as a function of fluid phase conductivity. Figure 1 depicts zeta potential values for intact yeast cells, cation exchange beads, and anion exchange beads in phosphate buffers of varying conductivities. The zeta potential has been reported as a main parameter affecting yeast cell deposition onto beaded adsorbents, particularly onto anion exchangers. ${ }^{5}$ Intact yeast cells, harvested at the late exponential phase of growth, showed zeta potential values $\approx-25 \mathrm{mV}$ at very low buffer concentration $\left(0.7 \mathrm{mS} \mathrm{cm}^{-1}\right)$. At standard ion exchange mobile phase composition, e.g. $\sim 20 \mathrm{mmol} \mathrm{L}^{-1}$ phosphate, $\mathrm{pH} 7.6$, zeta potential values were $-18 \mathrm{mV}$. Lower zeta potential values were observed with increasing conductivity, i.e., $-6 \mathrm{mV}$ at $34 \mathrm{mS} \mathrm{cm}$. A similar trend was observed when studying the effect of mobile phase conductivity on the electrokinetic behaviour of the cation exchanger beads.

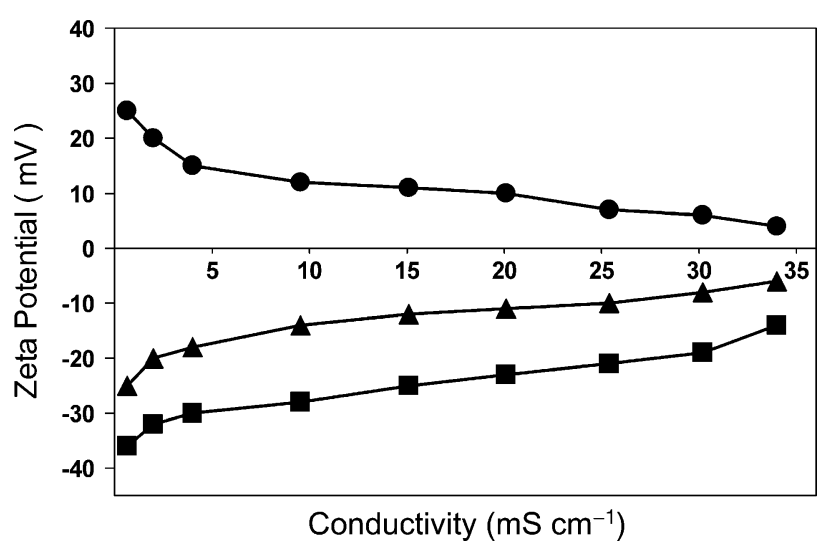

Figure 1. Zeta potentials of intact yeast cells and adsorbent beads as a function of fluid phase conductivity at $\mathrm{pH}$ 7.6. $\boldsymbol{\Delta}$, intact yeast cells; $\mathbf{\square}$, SP beads; 0 , DEAE beads. 
SP Sepharose fragments were utilized for such studies in order to avoid errors derived from the settling of the intact adsorbent particles. Lower zeta potential values obtained were $-36 \mathrm{mV}\left(0.7 \mathrm{mS} \mathrm{cm}^{-1}\right)$, while maximum values were $-14 \mathrm{mV}\left(34 \mathrm{mS} \mathrm{cm}^{-1}\right)$.

A second factor recognized to influence biomass deposition onto process surfaces is cell or cell debris size and shape. ${ }^{18}$ In this study, both factors are kept constant since only intact yeast cells ( $8 \mu \mathrm{m}$ diameter) of spherical shape were utilized as model biomass.

Besides electrostatic forces (EL), electrodynamic Lifshitz-van der Waals forces (LW) are known to mediate biomass interactions. The LW interaction, which is predominantly attractive in microbial systems, is not influenced by the ionic strength ${ }^{19}$ but both the range and magnitude of the EL interactions decrease with increasing ionic strength due to shielding of surface charges. LW forces between intact yeast cells and agarose-based material can be described by a Hamaker constant $(A)$. The value for $A$, in this particular system, was previously calculated as $0.34 \mathrm{kT}$ from contact angle measurements; details will be published elsewhere. Obtained Hamaker constant value are in agreement with assumed values for various microbial systems. ${ }^{19}$

The so-called acid-base (AB) forces are also included in the XDLVO approach. ${ }^{3} \mathrm{AB}$ interactions were found to be a function of the nature of the process solid phase onto which cell adhesion took place. For agarose-based supports and yeast cells an average $\Delta G^{\mathrm{AB}}$ value was calculated as $+30 \mathrm{~mJ} \mathrm{~m}^{-2}$, indicating the repulsive nature of the $\mathrm{AB}$ component. ${ }^{14}$ This value is valid at closest distance of approximation between the interacting bodies $(1.57 \AA)$.

\section{Biomass deposition experiments}

Deposition experiments were performed in an automated chromatographic system for increased throughput and convenience of use. Figure 2 depicts the schematic illustration of the chromatographic set-up.

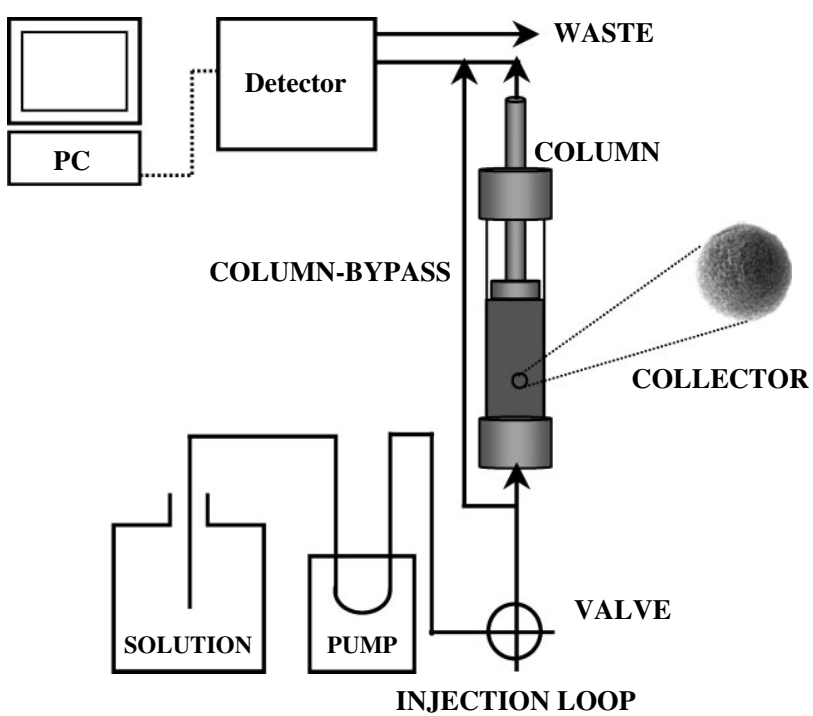

Figure 2. Schematic illustration of chromatographic system set-up.
In packed-bed systems, physical straining of biocolloids is considered to be significant on the basis of geometrical consideration when $d_{\mathrm{p}} / d_{\mathrm{c}}>0.05 .{ }^{9}$ In the system under study in this work $d_{\mathrm{p}} / d_{\mathrm{c}} \approx 0.04$ and thus physical straining can be neglected. Although straining has been observed when $d_{\mathrm{p}} / d_{\mathrm{c}}$ values were as low as $0.002,{ }^{16}$ experiments performed with the cation exchange material supported the previous assumption. No physical entrapment of the bio-colloids was observed within the packed-bed system since almost quantitative recovery of cells was verified under (chemical) non-deposition conditions (Fig. 3).

Hydrodynamic forces were kept constant within the laminar regime $(\operatorname{Re}<10)$ by maintaining a constant flow rate of $76.4 \mathrm{~cm} \mathrm{~h}^{-1}$. Therefore, biomass adhesion was evaluated under carefully controlled experimental conditions. Figure 3 illustrates typical run cycles for both 'interacting' and 'non-interacting' deposition systems. Each cycle is composed of an equilibration phase (20 PV), a sample (suspended biomass) pulse ( $\sim 10 \mathrm{PV})$, a washing step with running buffer (15 $\mathrm{PV}$ ), and (partial) regeneration with sodium hydroxide
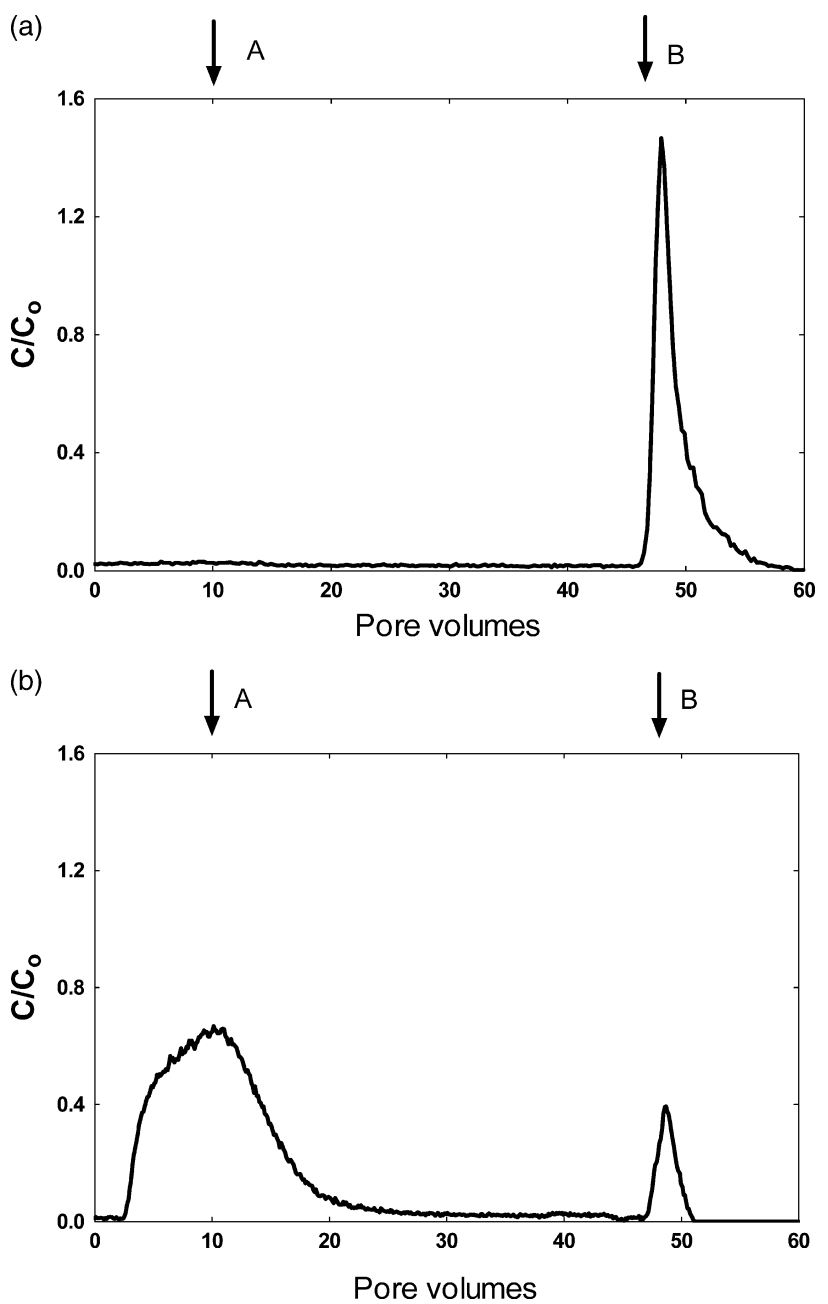

Figure 3. Typical experimental data as obtained from packed-bed experiments utilizing chromatographic beads as colloid collectors. Intact yeast cells were employed as a model. (a) Favourable deposition onto DEAE functionalized beads. (b) Unfavourable deposition onto SP functionalized support. The arrows indicate $(A)$ cell pulse injection and $(B)$ column regeneration with $0.5 \mathrm{~mol} \mathrm{~L}^{-1} \mathrm{NaOH}$. 
solution (20 PV). The breakthrough of biomass particles suspended in the effluent buffer can be observed in case (b), which corresponds to the partial deposition of cells onto the packed chromatographic beads. On the contrary, a strong deposition of cell is characterized by the experimental profile observed in case (a) where no suspended material is leaving the packed-bed system.

Employing the above-described methodology, systematic studies were performed to evaluate yeast cell deposition onto anion and cation exchangers. Figure 4(a) shows the family of deposition curves obtained by variation of fluid phase conductivity when
DEAE-Streamline ${ }^{\mathrm{TM}}$ beads were utilized as collectors. These adsorbent beads are weak anion exchangers and thus they are positively charged. Results are presented as normalised concentration $\left(\mathrm{C} / \mathrm{C}_{0}\right)$ versus pore volumes. In order to calculate $C / C_{0}$ absorbance data were employed since cell concentration was linearly related to such measurement within the concentration range involved in this study. The length of the biomass pulse, equivalent to $\sim 10 \mathrm{PV}$, was sufficient to produce a semi-complete breakthrough of suspended biological particles; i.e., the effluent cell concentration never reached $C_{0}$. It can be observed that total cell deposition took place at very low to low conductivity values,

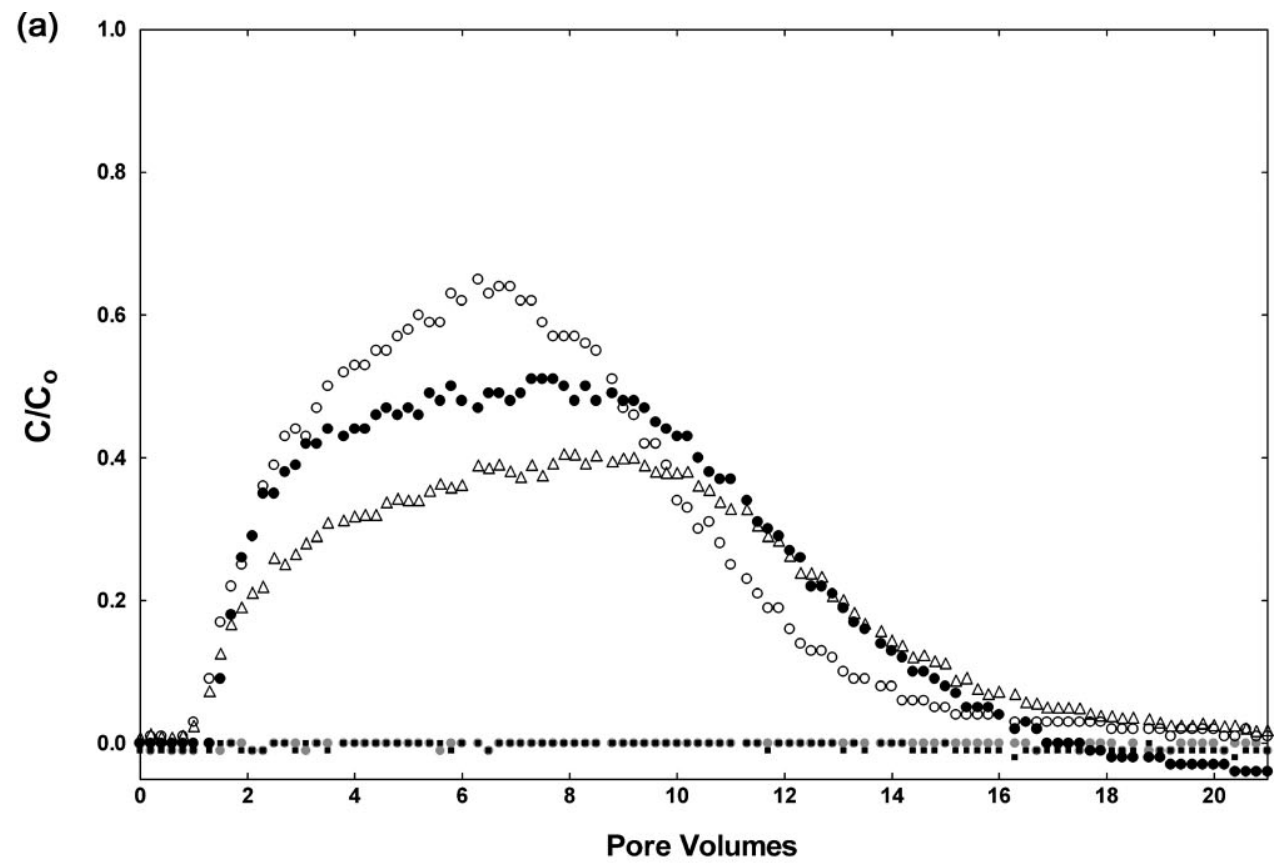

(b)

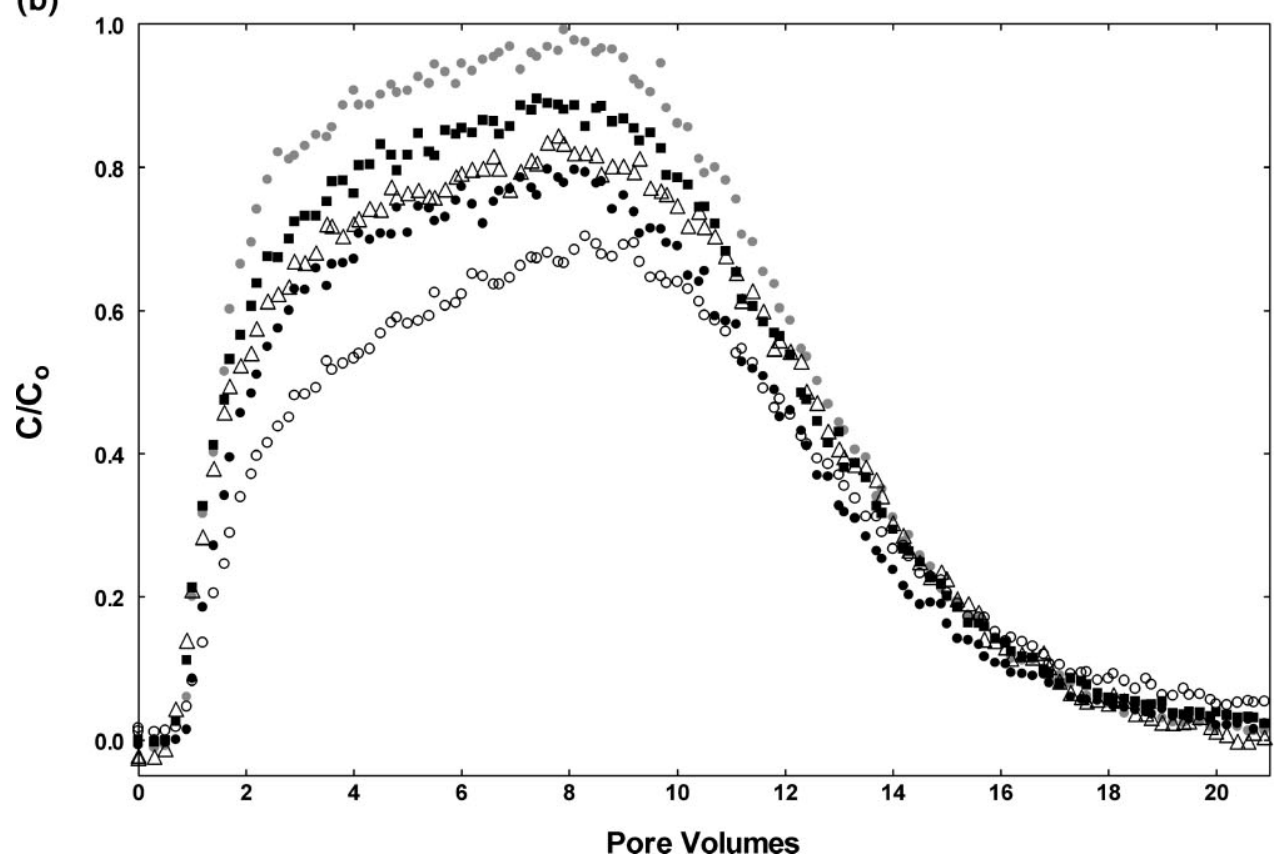

Figure 4. Normalized cell-effluent concentrations plotted against pore volumes pumped through the packed bed at different fluid phase conductivity values ( $\mathrm{pH} 7.6)$. (a) DEAE/yeast cells. (b) SP/yeast cells:, $0.66 \mathrm{mS} \mathrm{cm}^{-1} ; \mathbf{\square}, 2.00 \mathrm{mS} \mathrm{cm}^{-1} ; \triangle, 8.4 \mathrm{mS} \mathrm{cm}^{-1}\left(5.5 \mathrm{mS} \mathrm{cm}^{-1}\right.$ in (b)); $14.00 \mathrm{mS} \mathrm{cm}^{-1}$; $0,36 \mathrm{mS} \mathrm{cm}^{-1}$. 
e.g. almost no cells were detected when conductivity was $\leq 2.0 \mathrm{mS} \mathrm{cm}^{-1}$. An increased conductivity of the mobile phase has allowed for a progressive increase in the number of cells leaving the system. These results can be explained considering a predominant role of EL forces in a system characterized by collectors and colloids harbouring opposite charges. Since other forces were kept constant, as well as the colloid size, the only mechanism expected to govern deposition is related to Coulomb-type effects. This is in agreement with previous studies focusing on zeta potential as a diagnostic parameter for biomass/support interactions. ${ }^{5}$

Similar experiments were performed utilising SPStreamline $^{\mathrm{TM}}$ (negatively charged) beads. The biomass breakthrough curves are presented in Fig. 4(b). As can be observed from this figure, lower conductivity values in the fluid phase have resulted in negligible deposition of cells onto the cation exchange collectors. However, increased conductivity ( $\geq 14 \mathrm{mS} \mathrm{cm}^{-1}$ ) has promoted biomass deposition onto the cation exchanger. This finding might have an impact on bioprocess design since this material has been considered as 'noninteracting' with particulate feedstock. ${ }^{20}$ However, deposition of intact yeast cells onto SP- Streamline ${ }^{\mathrm{TM}}$ beads can be inferred from XDLVO calculations as shown below. Practical consequences related to this behaviour during EBA capture of bioproducts could arise during product elution; i.e., since high-conductivity buffers are commonly employed, aggregative fluidization may develop, resulting in a diluted product fraction.

\section{Parameter calculation}

Bio-colloid deposition experiments, as shown in Fig. 4, depict cell breakthrough behaviour compatible with collector blocking or cell release from the packedbed system. This is demonstrated by the fact that in most experiments the normalized cell concentration $\left(C / C_{0}\right)$ did not raise a steady-state value after the initial dispersive curve region. Therefore, the initial clean bed $C / C_{0}$ for each experiment was taken for parameter calculations. This allowed the application of the colloid filtration theory, which is valid under clean bed conditions. ${ }^{11}$

Table 1 presents calculated values for both $k_{\mathrm{d}}\left(\mathrm{s}^{-1}\right)$ and $\alpha$ as a function of fluid phase conductivity. $k_{\mathrm{d} \text { fav }}$ data correspond to the experimental run performed with DEAE-Streamline ${ }^{\mathrm{TM}}$ beads as collectors under lowest conductivity $\left(0.6 \mathrm{mS} \mathrm{cm}^{-1}\right)$.

Evidence suggests that simple models for calculating $\alpha$ based on deposition in the secondary energy minimum can result in accurate prediction of biomass attachment to porous media. ${ }^{7}$ For the DEAEStreamline ${ }^{\mathrm{TM}} /$ yeast system, $\alpha$ values decreased from $\sim 1$ at very low conductivity to 0.23 at $\sim 39 \mathrm{mS} \mathrm{cm}^{-1}$. On the other hand, for the SP-Streamline $\mathrm{e}^{\mathrm{TM}} /$ yeast system, $\alpha$ values increased from $0.07\left(\sim 0.6 \mathrm{mS} \mathrm{cm}^{-1}\right)$ to $0.18\left(\sim 39 \mathrm{mS} \mathrm{cm}^{-1}\right)$. As a reference, $\alpha=1$ has the meaning of complete cell deposition onto the packed collectors. Figure 5 summarizes these results in
Table 1. Calculated parameters from packed-bed experiments where chromatographic supports were employed as cell collectors. Calculations were performed according to Redman et al. ${ }^{11}$

\begin{tabular}{lrcc}
\hline Conductivity $\left(\mathrm{mS} \mathrm{cm}^{-1}\right)$ & $C / \mathrm{C}_{0}$ & $k_{\mathrm{d}}$ & $\alpha$ \\
\hline DEAE Streamline ${ }^{\mathrm{TM}}-$ intact & yeast & & \\
0.66 & 0.003 & 0.246 & 1.00 \\
2.0 & 0.006 & 0.211 & 0.858 \\
8.4 & 0.075 & 0.107 & 0.435 \\
14.0 & 0.244 & 0.058 & 0.236 \\
38.6 & 0.254 & 0.056 & 0.229 \\
SP Streamline ${ }^{\mathrm{TM}}-$ intact yeast & & & \\
0.66 & 0.654 & 0.017 & 0.071 \\
2.0 & 0.568 & 0.023 & 0.095 \\
5.5 & 0.519 & 0.027 & 0.110 \\
14.0 & 0.445 & 0.033 & 0.136 \\
38.6 & 0.333 & 0.045 & 0.184 \\
\hline
\end{tabular}

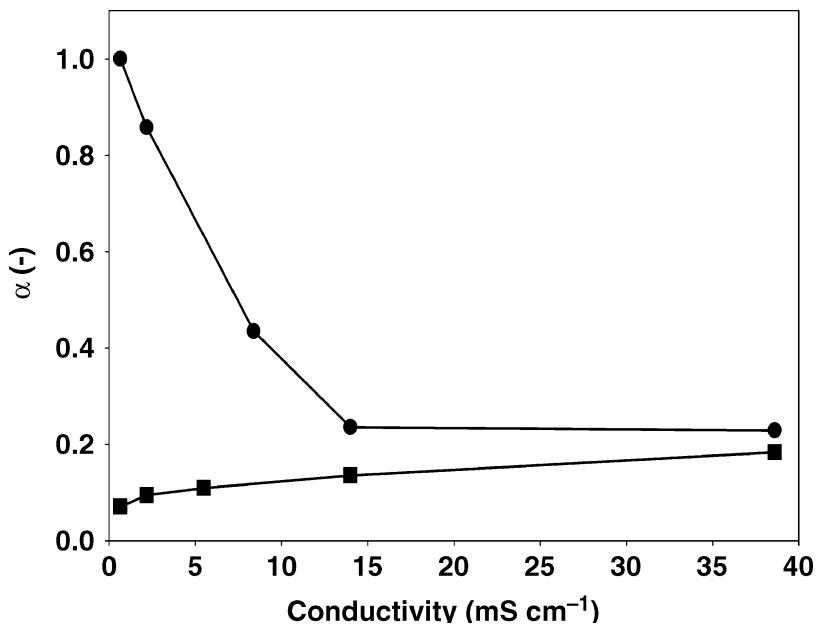

Figure 5. Changes in the attachment efficiency parameter $(\alpha)$ as a function of fluid phase conductivity. Deposition of intact yeast cell was studied for (@) DEAE and ( $\square$ ) SP chromatographic materials.

graphic form. Minimum $\alpha$ values were obtained for the anion exchanger system, which are nearly equivalent to $\alpha$ values obtained for SP-Streamline ${ }^{\mathrm{TM}}$ beads at $39 \mathrm{mS} \mathrm{cm}^{-1}$. These results indicate that biomass deposition experiments are an appropriate design tool to evaluate biomass deposition onto process surfaces. On the basis of the preceding experimental evidence, $\alpha$ is proposed as a diagnostic parameter that provides information on biomass attachment onto process surfaces. Applying the proposed methodology, changes in $\alpha$ can be effectively utilized to monitor biomass-support interactions even in cases where such interaction was overlooked in the past. ${ }^{20}$

\section{Bio-colloid deposition in the secondary minimum}

Figure 6 depicts total interfacial energy profiles as a function of the distance between two interacting bodies ( $U^{\text {TOT }}$ versus $H$ ) in aqueous media, i.e. diluted buffer solutions. Calculations were performed considering the role of LW, AB, and EL forces as previously reported, ${ }^{19}$ by utilizing data from contact angle measurement and zeta potential determinations. ${ }^{14}$ Therefore, the presented profiles are in accordance to the 
extended DLVO approach. Since the radius of the chromatographic beads is much higher than the radius of the intact yeast cell, total free energy was computed assuming a plane-to-sphere geometry.

Figure 6(a) represents XDLVO energy profiles for the system where a DEAE-Streamline ${ }^{\mathrm{TM}}$ bead interacts with an intact yeast cell. It can be observed that a secondary energy minimum exists at a distance of $\approx 5 \mathrm{~nm}$, where deposition of the cell particle can occur. This is essentially a reversible interaction that can be overcome by sufficient energy input for example, in the form of shear or hydrodynamic stress. The magnitude (depth) of the energy pocket, however, increases upon modification (reduction) of the liquid phase conductivity. As a consequence, stronger deposition of cell particles is expected when working with diluted buffers than when working with buffers/salt solutions with higher conductivities. This situation is reflected by the biomass deposition experiments as presented in Fig. 4(a). Therefore, this kind of experiment can confirm the trends predicted by XDLVO calculations. Both $U^{\mathrm{TOT}}$ versus $H$ calculations and deposition experiments are in full agreement with the known biomass interaction behaviour for DEAE-Streamline ${ }^{\mathrm{TM}} \cdot{ }^{21-23}$ Moreover, biomass deposition experiments can offer a simple
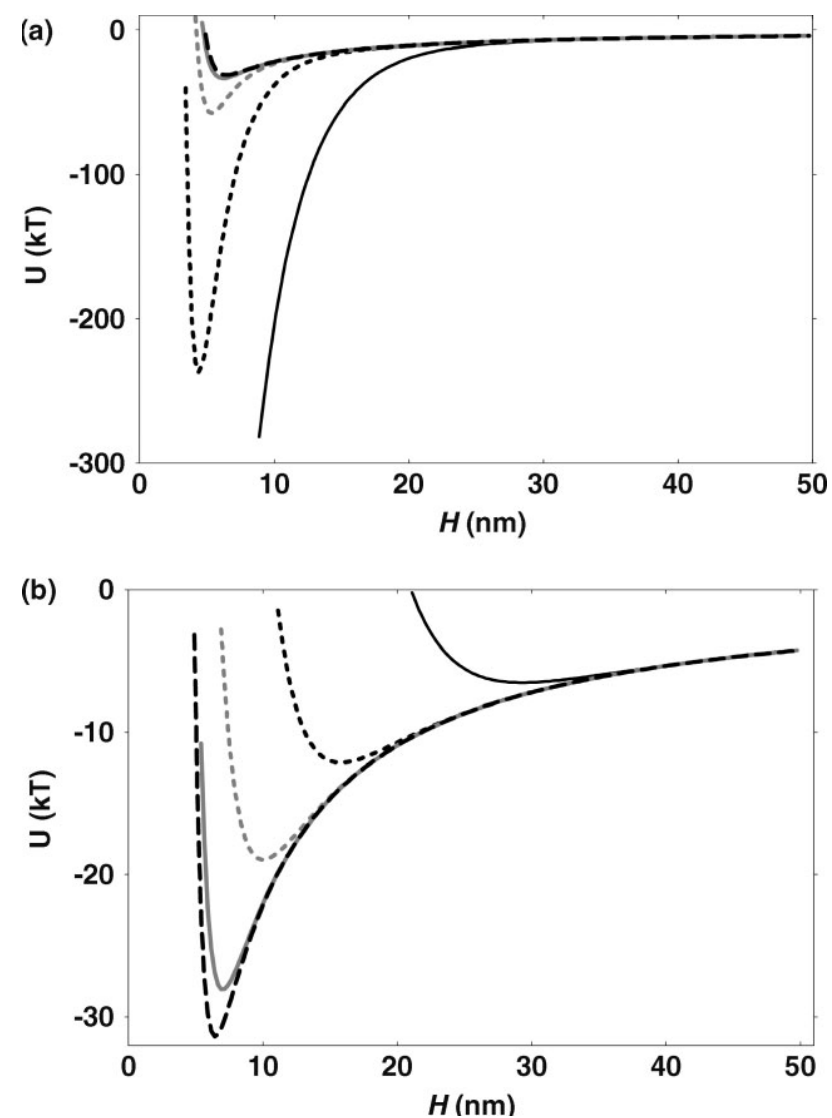

Figure 6. Calculated XDLVO total interaction energy as a function of separation distance. (a) DEAE/yeast cells. (b) SP/yeast cells. A family of curves representing variations in the conductivity value of the fluid phase is shown (black line, $2 \mathrm{mS} \mathrm{cm}^{-1}$; black dotted line, $4 \mathrm{mS} \mathrm{cm}^{-1}$; grey dotted line, $9.55 \mathrm{mS} \mathrm{cm}^{-1}$; grey line, $15.1 \mathrm{mS} \mathrm{cm}^{-1}$; dashed line, $34 \mathrm{mS} \mathrm{cm}^{-1}$ ). way to access interfacial phenomena in aqueous media. These phenomena have relevance from the bioprocess point of view and have important consequences for appropriate process optimization and material design.

Figure 6(b) represents energy profiles for the system where an SP-Streamline ${ }^{\mathrm{TM}}$ bead interacts with an intact yeast cell. In this case, secondary energy pockets can also be observed. Minimum free energy, according to XDLVO calculations, occurs at distances between $30 \mathrm{~nm}$ and $7 \mathrm{~nm}$. However, when compared to the minimum energy values observed for the anionexchange/yeast system, the SP-Streamline ${ }^{\mathrm{TM}}$ material promotes the formation of much less deep pockets, e.g. -5 to $-30 \mathrm{kT}$ (SP) as compared to -30 to $-1000 \mathrm{kT}$ (DEAE). It can also be realized that an opposite interaction behaviour takes place for this system; i.e., the depth of the energy pocket increases with the increase in fluid phase conductivity. This behaviour is again reflected by the biomass deposition experiments, confirming that these experiments are sensitive and able to reveal previously unrecognized underlying phenomena.

\section{Correlation with interaction energy profiles}

The correlation between the biomass deposition parameter $(\alpha)$ and the value of the free interfacial energy minimum (energy pocket) is shown in Fig. 7. This picture summarizes data gathered from ion-exchanger chromatographic matrices (DEAEStreamline $^{\mathrm{TM}}$ and SP-Streamline ${ }^{\mathrm{TM}}$ ) interacting with intact yeast cells, under the range of fluid phase conductivity values reported in this work $(0.66-38.6 \mathrm{mS}$ $\mathrm{cm}^{-1}$ ). In a previous study, ${ }^{14}$ we demonstrated that energy pockets - as calculated by the XDLVO theory-showing energy minima $\geq-20 \mathrm{kT}$ are not deleterious during product capture for example, by expanded bed adsorption. From Fig. 7 it $\alpha \leq 0.15$ can be proposed as a cut-off value for negligible biomass deposition. Therefore, as long as $\alpha$ is kept low enough, efficient fluidization and sorption performance can be anticipated.

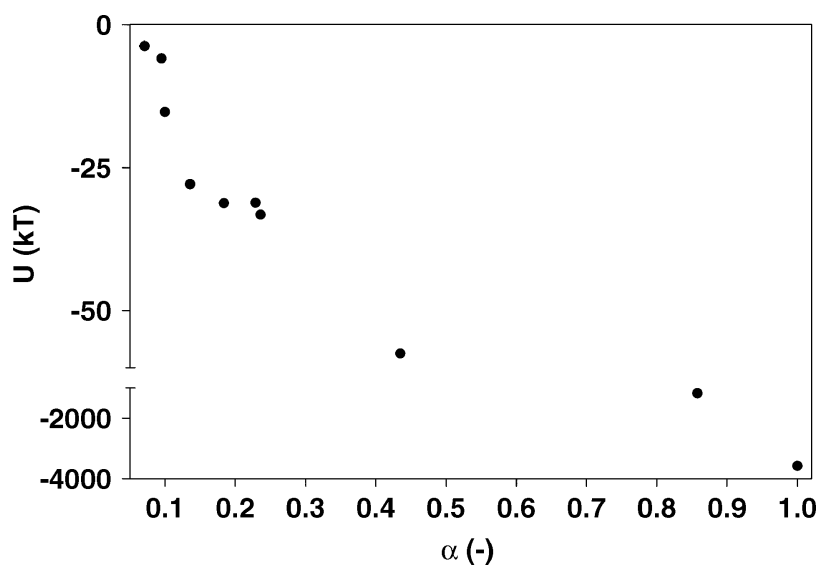

Figure 7. Correlation graph between the attachment efficiency parameter $(\alpha)$ and the total interaction energy according to the XDLVO approach. 
Besides biomass deposition, as expressed by the deposition parameter $(\alpha)$, the cell breakthrough profiles observed in Fig. 4 might indicate that a blocking phenomenon is also occurring in the systems under study. Blocking refers to the fact that cells which are already attached to the solid support can interfere with the attachment of further cells being contacted with the adsorbent beads. This phenomenon, usually accounted for by the so-called excluded area parameter $(\beta)$, has important environmental implications. ${ }^{24}$ During direct capture of bioproducts, due to the presence of much higher concentration of biomass ( $\sim 8 \%$ wet weight) in contact with the beaded adsorbents, blocking can be supposed to play a less significant role. Therefore, modelling approaches have been kept simple enough so as to provide a single parameter $(\alpha)$, which reflects biomass attachment as an important event having practical consequences for the performance of a direct capturing unit operation.

Biomass multilayer formation would also occur at long contact time and/or high biomass concentration, which is not the case for the biomass deposition experiment as described here. This phenomenon could be more important in cases where cell-to-cell aggregation or 'ripening' is favoured, like during hydrophobic interaction chromatography. An understanding of cellto-cell aggregation would require independent experimental methods to be evaluated. ${ }^{25}$

\section{CONCLUSIONS}

Biomass deposition experiments were performed in an automated workstation utilizing a packed-bed format and intact yeast cells in the late exponential phase of growth as a biomass model.

Under carefully controlled experimental conditions, removal of biomass particles onto chromatographic collectors was assumed to be dependent on (a) mass transfer, i.e., the transfer of a biological particle from the bulk liquid phase to the adsorbent bead, and (b) the capture of a biological particle onto an adsorbent bead by interfacial forces. Straining was neglected since the size of the biomass-derived particles is much smaller than the process beads. Detachment was also supposed to be insignificant under laminar flow conditions. The description of 'aggregation' (cell-to-cell), which implies multilayer adhesion, was omitted since this phenomenon takes place at high biomass concentrations and long contact times.

Cell deposition was systematically evaluated as a function of fluid phase conductivity and quantitatively expressed as a biomass deposition parameter $(\alpha)$. Deposition onto commercial anion-exchange beads was observed to increase with decreasing conductivity values in the mobile phase. The opposite behaviour was observed when cation-exchange beads were utilized as collectors in the packed-bed system. In both cases, experimental deposition studies confirmed predictions based on the free energy of interaction according to the XDLVO theory. Coulomb-type interactions were dominating since EL forces are affected by the ionic strength of the aqueous media surrounding the interaction bodies. Other forces that are relevant to the evaluation of biomass deposition were kept constant. The evaluation of LW and $A B$ forces is mandatory when comparing microbial strains and/or process materials apart from the model system employed in this work.

The biomass deposition parameter ranges from 0 to 1 and defines the probability that a bioparticle will adhere to a surface upon collision. $\alpha$ can be viewed as a single value when a fixed transport distance is assumed. A value for $\alpha \leq 0.15$ was established as a criterion to reflect insignificant biomass adhesion to the process support(s). It should be pointed out that this $\alpha$ cut-off value is valid under the experimental conditions described in this work, which are easily matched by utilization of commercial chromatographic systems and columns.

The bio-colloid deposition experiment can be proposed as a simple diagnostic tool for the evaluation of biomass interference during direct capture of bioproducts. Moreover, the biomass deposition method results in a novel approach for testing biomass/support compatibility, which is easy to implement in a standard chromatographic workstation.

\section{ACKNOWLEDGEMENTS}

This work was partially funded by the Inter-American Development Bank (BID) 1201/OC AR 649 PICT 08352 and a start-up grant from Jacobs University (IUB/2130-90050). Dr Canan Tari was supported by the International Centre for Transdisciplinary Science (ICTS) at Jacobs University and by TUBITAK (The Scientific and Technological Research Council of Turkey, Ankara, Turkey).

\section{REFERENCES}

1 Hubbuch J, Thommes J and Kula MR, Biochemical engineering aspects of expanded bed adsorption. Adv Biochem Eng Biotechnol 92:101-123 (2005).

2 Northelfer F and Walter JK, A comparison of STREAMLINE expanded bed adsorption with the combined techniques of filtration and conventional fixed bed chromatography for the capture of an $\mathrm{Fc}$-fusion protein from $\mathrm{CHO}$ cell culture. Application note 18-1144-87, Amersham Biosciences, Little Chalfont, UK (2002).

3 Van Oss CJ, Interfacial Forces in Aqueous Media. Marcel Dekker, New York (1994).

4 Lin DQ, Brixius PJ, Hubbuch JJ, Thommes J and Kula MR, Biomass/adsorbent electrostatic interactions in expanded bed adsorption: a zeta potential study. Biotechnol Bioeng 83:149-157 (2003).

5 Lin DQ, Zhong LN and Yao SJ, Zeta potential as a diagnostic tool to evaluate the biomass electrostatic adhesion during ion-exchange expanded bed application. Biotechnol Bioeng 95:185-191 (2006).

$6 \mathrm{Li} \mathrm{B}$ and Logan BE, Bacterial adhesion to glass and metal-oxide surfaces. Colloids Surf B Biointerfaces 36:81-90 (2004). 
7 Tufenkji N, Modeling microbial transport in porous media: traditional approaches and recent developments. Adv Water Resour 30:1455-1469 (2007).

8 Brown DG and Jaffe PR, Effects of nonionic surfactants on bacterial transport through porous media. Environ Sci Technol 35:3877-3883 (2001).

9 Rijnaarts HHM, Norde W, Bouwer EJ, Lyklema J and Zehnder AJB, Bacterial deposition in porous media related to the clean bed collision efficiency and to substratum blocking by attached cells. Environ Sci Technol 30:2869-2876 (1996).

10 Unice KM and Logan BE, Insignificant role of hydrodynamic dispersion on bacterial transport. F Environ Eng 126:491-500 (2000).

11 Redman JA, Walker SL and Elimelech M, Bacterial adhesion and transport in porous media: role of the secondary energy minimum. Environ Sci Technol 38:1777-1785 (2004).

12 Nascimento AG, Totola MR, Souza CS, Borges MT and Borges AC, Temporal and spatial dynamics of blocking and ripening effects on bacterial transport through a porous system: a possible explanation for CFT deviation. Colloids Surfaces B: Biointerfaces 53:241-244 (2006).

13 Ganeva V, Galutzov B and Teissie J, Flow process for electroextraction of intracellular enzymes from the fission yeast, Schizosaccharomyces pombe. Biotechnol Lett 26:933-937 (2004).

14 Vennapusa RR, Cabrera R, Ganeva V and Fernandez-Lahore HM, Direct capture from electro-permeabilized yeast cells on expanded beds: a biomass-adsorbent interaction study via surface energetics, in 6th European Symposium on Biochemical Engineering Science, book of abstracts (2006).

15 Ottewill RH and Shaw JN, Electrophoretic studies on polystyrene lattices. F Electroanal Chem 37:133-142 (1972).

16 Tufenkji N, Miller GF, Ryan JN, Harvey RW and Elimelech M, Transport of Cryptosporidium oocysts in porous media: role of straining and physicochemical filtration. Environ Sci Technol 38:5932-5938 (2004).
17 Tufenkji $\mathrm{N}$ and Elimelech $\mathrm{M}$, Correlation equation for predicting single-collector efficiency in physicochemical filtration in saturated porous media. Environ Sci Technol 38:529-536 (2004).

18 Hubbuch JJ, Brixius PJ, Lin DQ, Mollerup I and Kula MR, The influence of homogenisation conditions on biomass-adsorbent interactions during ion-exchange expanded bed adsorption. Biotechnol Bioeng 94:543-553 (2006).

19 Bos R, van der Mei HC and Busscher HJ, Physico-chemistry of initial microbial adhesive interactions: its mechanisms and methods for study. FEMS Microbiol Rev 23:179-230 (1999).

20 Feuser J, Walter J, Kula MR and Thommes J, Cell/adsorbent interactions in expanded bed adsorption of proteins. Bioseparation 8:99-109 (1999).

21 Fernandez-Lahore HM, Geilenkirchen S, Boldt K, Nagel A, Kula MR and Thommes J, The influence of cell adsorbent interactions on protein adsorption in expanded beds. $\mathcal{f}$ Chromatogr A 873:195-208 (2000).

22 Lin DQ, Fernandez-Lahore HM, Kula MR and Thommes J, Minimising biomass/adsorbent interactions in expanded bed adsorption processes: a methodological design approach. Bioseparation 10:7-19 (2001).

23 Fernandez-Lahore HM, Kleef R, Kula $M$ and Thommes J, The influence of complex biological feedstock on the fluidization and bed stability in expanded bed adsorption. Biotechnol Bioeng 64:484-496 (1999).

24 Bolster CH, Mills AL, Hornberger GM and Herman JS, Effect of surface coatings, grain size, and ionic strength on the maximum attainable coverage of bacteria on sand surfaces. $\mathcal{F}$ Contam Hydrol 50:287-305 (2001).

25 Ramachandran V and Fogler HS, Multilayer deposition of stable colloidal particles during flow within cylindrical pores. Langmuir 14:4435-4444 (1998). 